\title{
Exploring Ethnic Minority First-Year College Students' Well-Being and Sense of Belonging: A Qualitative Investigation of a Brief Intervention
}

\author{
Terrell L. Strayhorn ${ }^{1}$ \\ Virginia Union University, Richmond, USA
}

\begin{abstract}
Sense of belonging is associated with students' social adjustment and academic success, especially during the first-year of college. In this study, ethnic minority first-year college students were exposed to a brief belonging video intervention designed to alter self-beliefs, antisocial behaviors and personally threatening interpretations of academic-related adversities. Using an innovative qualitative approach, the researcher assessed college students' perceptions of the intervention on their health, well-being, and sense of belonging in the first year. Findings reveal that the video intervention helped first-year college students of color at PWIs reframe negative academic, financial, and social experiences while facilitating supportive networks, community, and belonging. Implications for research, policy, and practice are delineated.
\end{abstract}

KEYWORDS: qualitative research, sense of belonging, college students, intervention.

Successful students are healthy students indeed. The weight of empirical evidence consistently shows that the health and well-being of students is most certainly correlated with their academic success, although success factors vary from study to study (Ronzi et al., 2018). For instance, social isolation and loneliness seem to harm students' academic achievement, subjective well-being, and even their immune function and health (Civitci \& Civitci, 2009; Huo \& Kong, 2014). This seems critically important as recent data from the Centers for Disease Control and Prevention (CDC), as well as latest information from the Higher Education Research Institute (HERI), indicate that loneliness is a growing problem and negatively impacts a large number of college students, especially in their first year, according to researchers (Diehl et al., 2018; Moeller \& Seehus, 2019; Soni, 2019; Stolzenberg, 2018).

One psychological factor that may seem as a buffer against the negative impacts of social isolation and loneliness on college students' academic and physical health and well-being is sense of belonging, or the nature of students' positive relationships with others on campus (Gopalan \& Brady, 2020; Strayhorn, 2019). Although many definitions exist, belonging has been posited as "students' perceived social support on campus, a feeling or sensation of connectedness, the experience of mattering or feeling cared about, accepted, respected, valued by, and important to the group (e.g., campus community) or others on campus" (Strayhorn, 2012, p. 3). Prior research has shown that sense of belonging is critically important for finding value in life (Guo \& Cheng, 2016; Lambert et al., 2013) and it is a significant predictor of grades (Anderman \& Freeman, 2004),

1 Corresponding Author: Provost and Professor, Urban Education at Virginia Union University. E-Mail: tlstrayhorn@vuu.edu 
especially among ethnic minority students who may be uncertain about their sense of belonging in social institutions like college (Strayhorn, 2008a, 2008b; Walton \& Cohen, 2011). But more information is needed to understand how ethnic minority students in their first year of collegeone of the most difficult in terms of transition-describe their experiences and belonging (Upcraft et al., 2005).

Several studies have shown that student sense of belonging seems to be malleable and responsive to programmatic and policy intervention, including brief academic interventions (Walton \& Cohen, 2011; Yeager \& Walton, 2011). Yet, there is a clear need for more information about the efficacy of scalable interventions for improving students' sense of belonging in college (Stebleton et al., 2014), especially among ethnic minority students. A recent study examining the impact of a brief video intervention on first-year students' sense of belonging at a historically Black college/university (HBCU) during a 4-week summer bridge program produced positive results (Strayhorn, 2021). But more information is needed about whether and how academic interventions change "people's subjective interpretation of ambiguous events," such as daily challenges in college (Walton \& Cohen, 2011, p. 1451) among ethnic minority first-year students at predominantly White institutions (PWIs). This is the gap addressed by the present study.

This study breaks new ground on this topic by not only investigating these factors among ethnic minority first-year college students at PWIs, but also employing qualitative methods judiciously as a way of conducting intervention research, in keeping with expert guidance (Sandelowski, 1996). Contrary to popular belief, qualitative methods "can be used to enhance the significance and harness the benefits of [non]clinical [intervention] trials...clarifying [how] interventions [impact individuals] in their real-life contexts" (p. 359). Furthermore, Stebleton et al. (2014) urged scholars to "conduct qualitative studies that explore the meaning of...students' lived experiences related to belonging" (p. 17). For this reason, qualitative methods were employed to investigate the main purpose.

\section{Purpose and Research Questions}

The purpose of the present study is to understand the influence of a brief belonging intervention on first-year, ethnic minority college students' well-being and sense of belonging generally and, specifically, the meaning that students make of school-related adversities (e.g., isolation, setbacks) after viewing a brief video intervention. Two research questions guided the investigation:

1. How do ethnic minority first-year college students describe their overall health, well-being, and sense of belonging (pre-intervention)?

2. How does a brief video intervention influence first-year students' interpretations of schoolrelated adversities, in their own words (post-intervention)?

\section{Literature Review}

To conduct this study, it was necessary to closely examine the literature in three primary areas. First, it was useful to review prior research on first-year summer bridge programs as one type of pipeline or pathway initiative. Second, previous scholarship on college students' sense of belonging was relevant for this study, including any intervention studies. Lastly, I appraised the literature on using qualitative methods in intervention research. Thus, the literature review is organized around these topics. 


\section{Summer Bridge Programs}

Scholars have posited summer bridge programs (SBPs) as one type of pipeline, pre-college, or pathway initiative (Gándara, 2001; Myers \& Schirm, 1999). Pipeline initiatives are one of the oldest strategies used to increase student enrollment and eventual success in higher education (Bailit et al., 2005; Tierney, 2002). What is known about SBPs focuses on the program's primary purposes (Swail \& Perna, 2002), the degree to which culture is infused in the curriculum (Villalpando \& Solórzano, 2005), and the important role that parents play in students "getting ready" for and "getting into" college (Gándara, 2002a, 2002b; Swail \& Perna). For instance, studies have shown that participating in a summer bridge program yields the greatest impact on students from low-income families and helps improve student transitions by increasing their college knowledge, academic and social skills (Myers, 2003). Others have found that SBPs help ease social adjustment to the academic and social demands of college life (Sablan, 2014).

Other studies examine the impact of SBPs on undergraduate student retention and academic achievement in college (Felder et al., 1995; Fletcher et al., 2001; Garcia, 1991; Moller-Wong \& Eide, 1997). For instance, Garcia (1991) conducted an evaluation across 19 California State University campuses and found that SBP participation was associated with higher retention rates in the first- and second-year of college. Similarly, Felder et al. found that first-year retention rates were higher for women who participated in the WISE summer bridge program than their nonbridge counterparts. While these studies provide fairly persuasive support for SBPs, Coles (1993) once said, "It is [still] surprising how little empirical data exists about the program effectiveness in terms of ...preparation rates or [specific] strategies that make the most difference" (p. 25). Recently, SBP scholars have turned their attention to specific programmatic elements that are likely to yield the greatest benefit for students such as academic interventions like "workshops on time management, financial literacy, or other topics related to navigating campus resources" (Sablan, 2014, p. 1036). Little is known, however, about the efficacy of academic interventions, embedded within SBPs, targeting sense of belonging, which has shown to be critical for college success (Strayhorn, 2019).

\section{Sense of Belonging in College}

Sense of belonging is a basic human need that affects human behaviors (Maslow, 1954). Higher education research on students' sense of belonging is growing expansive. For example, Hurtado and Carter (1997) analyzed survey data from 272 Latino students at over 100 colleges and found that sense of belonging was positively associated with educationally purposeful engagement with peers and faculty. Sense of belonging is also correlated with greater college satisfaction and both improved academic- and health outcomes among minority students (Carales \& Nora, 2020; Ostrove \& Long, 2007).

College students' sense of belonging ascends in importance at certain times, under certain conditions, and in particular places when and where individuals holding marginalized or minoritized $^{2}$ identities are prone to feel anxious, stereotyped, or vulnerable for alienation, isolation, or rejection, like the first-year of college (Bui, 2002; Strayhorn, 2019). For instance, Garvey et al. (2020) analyzed survey data from 390 first-year, first-generation undergraduates living in residence halls at a large public university. They found that women reported higher rates of belongingness

\footnotetext{
2 I use the term "minoritized" to acknowledge and refer to the systemic subjugation, underrepresentation, subordination and oppression of people of color in some U.S. social institutions such colleges and schools, in keeping with others (Harper, 2012). It is used interchangeably with ethnic/racial "minority" in this paper.
} 
compared to men; similar results were found for students from high income backgrounds. Firstgeneration freshmen who interacted with staff and peers within residential environments experienced increased belonging. Other studies suggest that sense of belonging may even act as a buffer against the negative effects of stereotypes in college classrooms (Freeman et al., 2007), although findings await additional empirical testing in postsecondary contexts.

More recent studies have shown that students' sense of belonging tends to be malleable and responsive to programmatic intervention. For instance, Walton and Cohen (2011) conducted a randomized controlled trial with 92 college freshmen to test the effects of a brief social belonging intervention (i.e., writing essays) on academic and health-related consequences over three years. They found that the belonging intervention raised students' grade point average (GPA) relative to multiple control groups and improved self-reported health and well-being, with pronounced benefits to African American students. Similar results were found in a recent quasi-experimental study of first-year students in a 4-week SBP at an HBCU (Strayhorn, 2021).

\section{Qualitative Methods in Intervention Studies}

Few belonging scholars have focused on better understanding how academic interventions shape college student's beliefs, feelings, and subjective construal of school-related adversities using qualitative methods. Scholars have long argued for and found value in using qualitative methods in intervention research (Willms et al., 1990), although these approaches are rarely used in higher education studies. In fact, qualitative methods are superior to quantitative designs in their ability to "permit the researcher to be data-driven, particularly with regard to [lived] experiences and the natural setting of [such] experiences" (Willms et al., p. 392). Miles and Huberman (1984) explained that field-based qualitative research is better at "local causality," or developing explanations of actual events and processes that lead to specific outcomes. Indeed, use of qualitative methods in intervention studies has increased over time, across trial registries, mostly when evaluating a behavioral intervention (O'Cathain et al., 2013). For these reasons, qualitative methods made a logical choice for studying the impact of a brief video intervention on ethnic minority first-year college students' sense of belonging and academic-/health-related outcomes. The study was conducted according to the methods described in the next section.

\section{Methodology}

The present study employs qualitative methods to understand racially minoritized first-year college students' health, well-being, and belonging experiences, as well as any shifts in their interpretations of school-related adversities after watching a brief video intervention. This study is part of a larger research program that centers on college students' sense of belonging (Strayhorn, 2019) with a principal stream focusing on the efficacy of brief, scalable interventions that, though relatively low-cost, might have profound effects on student outcomes, especially for racially minoritized students attending PWIs and HBCUs in the United States.

Though the larger study consists of both quantitative and qualitative components across diverse samples and different belonging interventions developed by the author, the study's data are primarily qualitative notwithstanding inclusion of some quantitative insights drawn from the demographic questionnaire. Despite the presence of a few numbers, I made a conscious decision against naming this a mixed methods design in consonance with the study's primary objectives and my understanding of such designs. Mixed methods design strives to integrate quantitative and qualitative data through a transformative process, not merely "qualitizing quantitative" information (Tashakkori \& Teddlie, 1998, p.126), as was done herein. Like others, I want to avoid (mis)labeling 
studies that "merely employ both types of data" as mixed methods when there's no explicit mixing per se (Driscoll et al., 2007, p. 20). In short, I did not seek to explore or understand association between quantitative and qualitative data, neither did I aim to expand the breadth of investigation by offsetting the weaknesses of one approach with the strength(s) of the other, as would be the case in a truly mixed methods design (Creswell \& Plano Clark, 2007).

\section{Participants}

Thirty-five participants were included in this study. Each of them participated in a 5-week summer bridge program (SBP) for first-time, full-time entrants at a mid-sized liberal arts PWI in the southeastern region of the United States. Racial/ethnic minorities represent $22 \%$ of total enrollment at the institution under study. The vast majority of study participants are women (60\%), all are non-White/racial minorities, one-third are first in their family to attend college (i.e., firstgeneration) and $75 \%$ are Pell-eligible recipients. To participate in this study, the following criteria were applied: (1) At least 18 years old (2) first-time, full-time college freshman in the SBP and (3) willing and able to commit to an interview. All 35 participants met these criteria and voluntarily agreed to the study. Table 1 presents a summary.

Table 1

Descriptive summary of study participants $(N=35)$

\begin{tabular}{|c|c|c|}
\hline Characteristic & $\%$ & $\mathrm{~N}$ \\
\hline \multicolumn{3}{|l|}{ Sex } \\
\hline Men & 40 & 14 \\
\hline Women & 60 & 21 \\
\hline \multicolumn{3}{|l|}{ Race/Ethnicity } \\
\hline Black or African-American & 63 & 22 \\
\hline Latinx & 23 & 8 \\
\hline Asian Pacific Islander & 9 & 3 \\
\hline American Indian/Alaskan Native & 6 & 2 \\
\hline \multicolumn{3}{|l|}{ Age } \\
\hline 18-19 years & 77 & 27 \\
\hline $20+$ years & 23 & 8 \\
\hline \multicolumn{3}{|l|}{ Pell-Eligible } \\
\hline Yes & 74 & 26 \\
\hline No & 26 & 9 \\
\hline \multicolumn{3}{|l|}{ First-Generation } \\
\hline Yes & 30 & 11 \\
\hline No & 70 & 24 \\
\hline
\end{tabular}

Note. First-generation is defined as neither parent ever attended 4-year college. Percentages might not total " 100 " due to rounding.

\section{Data Collection}

Data were collected using two primary methods: demographic data questionnaire and interviews. The expressed purpose of interviewing is to "find out what is in and on someone else's mind" (Patton, 1990, p. 278). Semi-structured interviews were conducted with students in the late summer term. A typical interview lasted approximately 45 minutes on average, although they ranged from 30 to 75 minutes across the sample. Consistent with naturalistic design (Kvale, 1996), 
I allowed interview length to vary across participants because some needed more time than others to recall their experiences, explain their thoughts, and convey their feelings verbally.

The interview protocol included questions about students' college expectations, initial social experiences and anxieties (retrospective), and the nature of their relationships with SBP peers, faculty, and staff. One set of questions also intentionally gauged how the brief intervention video altered the meaning that students make of college-related adversities and challenges, if at all. A final set of interview questions asked students what they took from the video and how it influenced their interpretation of campus experiences, if at all. Additionally, all participants completed a demographic form that included a few survey-like items measuring their health behaviors (e.g., feeling lonely) and preferred pseudonym (or fictitious name). All interviews were audio-recorded and conducted by the author or a member of his research team with participants one-on-one or via small focus groups.

\section{The Intervention}

Interviews were conducted after students viewed a brief belonging intervention designed to encourage non-personal, nonthreatening interpretations of adversity. The 5-minute video, developed by the author, framed social isolation, loneliness, homesickness, rejection, and such experiences as normal, ordinary, non-threatening, temporal (or time-limited), surmountable, and encouraged students to interpret them as part of college life rather than evidence or "cues" that they do not belong. The experimental video intentionally included short vignettes featuring students of color (juniors, seniors, and recent graduates) talking plainly about their early college experiences, worries, setbacks, and racial realities at a PWI (e.g., being the only in a class). Vignettes were interwoven with animated messages (e.g., "You Matter" or "It Gets Better") and lists (e.g., campus support services) that acted as stimuli, designed to boost college knowledge and belonging, according to theory (Strayhorn, 2019). It is important to note that previous scholars have put forth that video represents an important "educational tool that can be [easily] integrated into the classroom [or learning environment] to increase awareness, facilitate learning, and influence attitudes" (Soble et al., 2011, p. 152).

\section{Data Analysis}

Data analysis proceeded in several steps. First, all transcripts were transcribed by a professional and entered into NVivo, a qualitative analysis software, used for storage of data, transcripts, codes, and larger themes first worked out by hand. Every transcript was read multiple times to gain a sense of the whole experience communicated by participants. Then, I analyzed transcripts through a line-by-line review of the text that led to categorization of individual chunks of text into codes; a form of open-coding. Codes were used to identify larger elements, called supercodes, that reflected student's experiences and perceptions. Ultimately themes were derived from that inductive process of comparing and contrasting codes and supercodes, combining those that were related while leaving intact those that stood alone, in consonance with my prior work (Strayhorn \& Tillman-Kelly, 2015). Demographic data from the questionnaire were analyzed using descriptive statistics and frequency counts.

Trustworthiness was established through several validity-enhancing techniques. For example, triangulation was achieved by searching for convergence among multiple and different data sources (i.e., demographic data form, interviews, and field notes). Field notes were recorded during the data collection process to log personal reflections, thoughts, and to chronicle decisions made about the research process (Denzin \& Lincoln, 2000). They were also useful for maintaining 
"precise records of who said what, when, where, and under what conditions" (Whitt, 1991, p. 45). Trustworthiness also was enhanced through peer debriefing. Lincoln and Guba (1985) define peer debriefing as "a process of exposing oneself to a disinterested peer in a manner paralleling an analytic session and for the purpose of exploring aspects of the inquiry that might otherwise remain only implicit within the inquirer's mind" (p. 308).

\section{Positionality}

Moustakas (1994) asserted that researchers should lay bare the known presuppositions and prejudices they may carry with them into the research process. This exercise in uncovering how the researcher situates self in relation to the phenomenon under study is known as positionality. In keeping with this perspective and the values of this journal, I recognized that my perspectives are shaped, in part, by my own experiences as a scholar of color who has studied SBPs, students of color, and sense of belonging for over a decade (e.g., Strayhorn, 2008b, 2012). That perspective is further fashioned by my experiences building summer bridge programs at two different institutions (Strayhorn, 2011), a PWI and an HBCU. By bracketing these influences, I consciously challenge and attempt to suspend the way they might limit or constrain my critical gaze in the present study.

\section{Limitations}

Like all investigations, this study is not without limitations. The sample consisted of 35 ethnic minority first-year college students. While this may be considered a fairly modest sample size by some readers, participants represented the entire population of all entering ethnic minority first-year students in the institution's summer bridge program during the period of study. Secondly, because the focus of qualitative research "is on depth, the emphasis is rarely on sheer number of participants" (Jones, 2002, p. 645). Rather, sample size depends on the research question(s), the study's purpose, and what is needed to know to yield authentic insights in response to the overarching inquiry. Study participants were in the best position to share their perspective about the influence of the brief intervention on their general perceptions, health, and well-being in the first year of college.

Another limitation is reflected in the fact that the researcher was not part of the SBP staff and, thus, an outsider to the community. As an outsider, participants may have been uncomfortable sharing their insecurities and vulnerabilities during the interview; ostensibly, this would limit findings in unknown ways. To address this issue and reduce the social distance between us, the researcher spent time visiting the SBP classes and social activities as a non-participating observer one day prior to data collection; he did not speak extensively to students or staff, neither did he reference the video or belonging. Silently observing the students, their activities, and experiences enhanced my thoughts about the study and its relevance to the lives of first-year, ethnic minority college students. Despite these limitations, the worth of the present study is not diminished.

\section{Findings}

The analytic process described in the previous section yielded important findings. Analysis of the demographic data form reveals interesting variability patterns in ethnic minority first-year college students' health behaviors, especially the frequency that respondents reported "worrying about academic success" (54\%), "feeling homesick" (31\%), and "feeling lonely" (23\%), to name a few. Over two-thirds of respondents indicated that they "used or experimented with substances" like alcohol, drugs, or pills as a way of coping with college-related anxiety and loneliness. Almost 
a third (29\%) reported drinking "more than 4 alcoholic drinks in a single sitting," while less than $10 \%$ reported "contemplating suicide." Table 2 presents a summary of these descriptive results.

\section{Table 2}

Summary of Participant's Health Behaviors

\begin{tabular}{lc}
\hline Health behavior(s) & \% High Frequency ${ }^{1}$ \\
\hline Feeling homesick & 31 \\
Stressing about money \& bills & 47 \\
Worrying about your academic success & 54 \\
Feeling lonely & 23 \\
Consuming 4 or more drinks in single sitting & 29 \\
Contemplating suicide & 8
\end{tabular}

${ }^{1}$ High frequency reflects the proportion of survey respondents who rated "often" (4) and "very often" (5) combined.

\section{Feelings Affect Health, Well-Being \& Belonging}

Participants spoke at length about the amount of time they spent worrying, feeling homesick, and lonely. Immediately after enrolling, many missed their family and friends, worried about their ability to excel in college, and felt lonely or "out of place," even when physically surrounded by others at times. One student shared:

It was pretty quick for me. I think like that same weekend. My parents dropped me off at [college] and we had a meeting for [the bridge program] that evening. By dinnertime, I was like...I can't do this. I miss my family. I miss my bed. I miss everything back home. It was like I just needed to get back [home].

Another student expressed similar sentiments:

I would definitely say it was hard at first. That first week or two, I thought like I was going to die [sic] (laughing). I stressed a lot. I cried a lot. About school, my family, my money, my boyfriend [back home]...it was legit depressing, no cap [translated "no lie"]. I started taking pills to sleep, relax...wake up (laughing). A lot of times, I felt like I'm here [at college] by myself, you know. It was like everyone kinda' [sic] moved on without me.

Participants also expressed how these feelings not only impacted their mental health and general outlook, but also diminished personal beliefs about their academic abilities and sense of belonging in college during the first year. For instance, one student who aspired to major in biology shared:

Thinking back to the first few weeks, I know I doubted myself a lot. It was hard for me because I didn't really like it here at first. I missed my twin [sister] and all my cousins. In high school I got this job-at the mall-and I really liked everybody there. But I had to leave to come here [to college] and it was like...boom, I'm here alone. I started thinking like if I don't like 
it here and I don't know anybody, then maybe I shouldn't be here, if that makes sense.

Others shared comments that echoed the same sentiments - that feelings and worries generally led to self-doubts about one's academic abilities and sense of belonging in college. Students used a range of words to describe shifts in their academic confidence (i.e., self-efficacy, in prior literature [Panadero et al., 2017]) like "dissed myself," "felt like I couldn't do it," and "stopped seeing myself as college material," to name a few.

Diminished beliefs in one's academic abilities significantly reduced the extent to which ethnic minority first-year students felt like they belonged in college. A number of participants shared how feelings and thoughts early on influenced their mental and physical health, which catalyzed shifts in their academic self-beliefs and subjective evaluation of their "place" in college. Consider the following:

It's just weird. Everybody was happy. I wasn't happy. Everybody was smiling. I wasn't smiling. Everybody was making friends and I was missing all mine [back home]. It was like, I don't know...I thought God was telling me: 'See, you aren't like them...you don't belong here.'

I'll never forget the first weekend...well, it was like the $2^{\text {nd }}$ because we moved in on the first one [i.e., weekend]. All them went out [sic], I think to like a bar or club or something. But I didn't go. I stayed [in the dorm], drank [alcohol], and FaceTimed my ex [boyfriend]. I felt so lame, like everybody hanging out except who? Me. I didn't fit in the box, ya' mean.

In summary, ethnic minority first-year college students participating in a summer bridge program described their first few weeks as generally challenging, isolating, and marked by frequent worrying about finances and academics, feeling homesick, and lonely. These feelings influenced their mental and physical health, as many reported using or experimenting with drugs and pills or drinking alcohol to cope with these issues. Feelings also catalyzed downward shifts in their selfbeliefs about their academic ability and seemed to reduce their sense of belonging in college.

\section{Influence of Intervention on Belonging}

In keeping with the study's design, all participants were exposed to a 5-minute brief intervention video designed to positively influence students' perceptions of academic challenges as described in Data Collection. After viewing the video, $100 \%$ of participants rated the intervention "positive" (versus negative) and "helpful" (versus harmful) on the demographic questionnaire. Despite this consensus, respondent's comments varied in terms of the video's influence on them, their interpretation(s) of college-related adversities, and consequently their sense of belonging in college.

General Perceptions of the Video. Participants praised several aspects of the video intervention. For example, key words and phrases typically associated with students' overall impressions of the video include: it's great, love the video, it's impactful, very inspirational, and it's short but sweet, as one put it. Students seemed to appreciate the video intervention's brevity. Lasting only about 5 minutes (or 300 seconds), the video maximizes the space of time with "powerful words of advice from students who've been here [i.e., first year], done this," as one explained in his interview. 
Apart from the short testimonials from juniors and seniors reflecting on their first year in college and how they overcame their struggles, the video intervention includes transition slides that display "uplifting messages that stick with [students]," as one admitted in his interview. "I agree with all of them that the video was dope... I liked hearing from [the junior student] but I also wrote a few of the inspirational quotes on my phone." Another student reported something similar: "Oh yeah, I took a picture of one with my phone so I could put it on IG [Instagram]... it say [sic], 'You matter. You are enough."' Brevity, relatability, and inspirational messaging were identified as positive attributes of the video intervention that enhanced ethnic minority first-year college students' confidence or self-efficacy, well-being, and outlook on college life. Beyond aesthetics, the video intervention had other results.

Video's Influence on Beliefs \& Belonging. In keeping with Sandelowski's (1996) advice about the utility of qualitative methods, participants described in rich detail how the brief belonging video intervention influenced their construal of campus experiences and thereby affected their sense of belonging. For instance, several participants explained how the video "changed [their] mind about things" and caused them to question why they assumed things wouldn't work out well for them in college. One student shared:

I wish I had seen it [the video] the first day of [college]. That could've really changed my mind about things. I wouldn't have been so depressed, thinking I'm the only one who don't want to be here sometimes [sic]. Now I know, it's like normal to just feel that way at first...it don't mean you can't still stay in college.

Another student spoke about her "aha moment" triggered by the video intervention:

That video was lit (laughing). No, for real, I'm gonna need a copy of that to watch every day. It put so much in perspective for me though. Like that lonely aspect [sic] ...that's not bad. It's like basic to feel that way or to feel stressed out 'cuz you're the only person of color in class. Even the SGA [Student Government Association] leader in the video was stressed they first year [sic]. So, why did I immediately jump to...OMG, I can't do it. Am I gonna flunk out of college?! I be so dramatic at times yo [sic].

Participants also pointed out that the video offered alternate perspectives and optimistic views "from real-life students like me," as one put it, which reduced students' self-doubts and boosted their confidence. Several students offered comments that affirmed the major themes of the brief video intervention. For example, consider the following:

That video they showed us...it was short, but it was really helpful. I especially liked it 'cuz it included snippets from real-life students like me...you know, who made it through their freshman year. Basically, they was like: 'Don't worry, it gets better;' 'Don't stress, you're not alone;' and 'Don't quit, 'cuz I didn't... and look at me now' (laughing). Since seeing it [the video], I think different [sic].

What I really got from the video was, like, it takes time to adjust. To make new friends. To get used to the amount of work. To find your groove, you know. It ain't gonna happen in the first week or two. Give it some time. 


\title{
That helped me feel better and now I felt like I could make it kinda like how they did.
}

By reducing self-doubts and boosting confidence, the video intervention also helped firstyear students in this study reframe their interpretation of school-related adversities (subjective construal) as common, transient, nonthreatening, and not an indication that they do not belong in college. One student put it this way:

\begin{abstract}
I think they [SPB staff] did that on purpose, showing us the video like that. It shined a whole new light for me. At first, I kept worrying like maybe I wasn't prepared for college or something. But since [the video], it's like things can't be so bad. You just got to give yourself time to get it...get your college groove on.
\end{abstract}

Other students shared similar sentiments. One self-identified first-generation student explained: "The video helped us all feel connected because we shared so much of that stuff [e.g., worrying] in common. That really strengthened us, I think." Sharing stories about their common feelings, anxieties, and self-doubts during the video intervention session also helped participants be more open, trusting, and vulnerable with other SBP peers and staff. Being able to be open, honest, and "let their hair down," as one put it, improved relationships and enabled students to feel safe expressing themselves authentically, which in turn, engendered a strong(er) sense of belonging in college.

\section{Discussion}

The purpose of this study was to understand the influence of a brief video intervention on first-year, ethnic minority college students' health, well-being, and sense of belonging generally and, specifically, the meaning that students make of school-related adversities (e.g., isolation, setbacks) after viewing the video as part of a SBP during the first year of school. Findings suggest efficacy of the brief belonging video intervention on minoritized first-year students' sense of belonging at a PWI. From participants comments, we learn that the video intervention helped firstyear students of color reframe and overcome negative experiences such as feeling homesick, being the only (member of their race) in class, worrying about school-related finances, and failing to make friends. Messages displayed or implied during the video intervention caused students to see these issues are normal, transient, common, and changeable, rather than an indictment against their sense of belonging in college. Results align with claims by Walton and Cohen (2011) based on an essay-based, written intervention, but reveal fresh insights about plausible underlying causal mechanisms associated with exposure to a brief video intervention for first-year college students of color at a PWI.

Consistent with a number of prior studies (Freeman et al., 2007), students in this study described their general and academic health and well-being at the start of college as challenging and uncertain, largely due to social adjustment issues brought on by college transitions. Over half of the SBP students in the sample reported worrying frequently about their academic success, while half stressed about money and school-related finance matters. A third of participants reported feeling homesick and almost one-quarter frequently felt lonely, confirming results presented elsewhere (Soni, 2019). Prior studies have shown that negative feelings, anxiety, and/or loneliness reduce academic achievement (Huo \& Kong, 2014), but findings from the present study extend that line of inquiry. First-year students of color in the sample explained in their own words that it's 
not the mere presence of such feelings that reduces their confidence, optimism, and certainty about belonging in college at the PWI they attend. Rather it is their interpretation-or the meaning they make - of such incidents that shapes their self-beliefs, physical and mental well-being, and sense of belonging. When such anxieties and concerns are interpreted and attached to fixed characteristics - like one's race - they erode self-confidence and deplete mental bandwidth in ways that compromise minoritized students' sense of belonging in a PWI context. However, participants help us understand that hearing from similarly-situated peers and learning about campus support services via the brief experimental video can mitigate these effects, raise well-being and boost belonging.

Whereas early on, students might have perceived social challengees (e.g., not making friends) and academic trouble as threatening, long-lasting, and related to their race, thus, an indication that they did not belong in college, exposure to the brief video intervention altered their interpretive lens, or subjective construal, as discussed in the literature (Walton \& Cohen, 2011). Initially, students of color in the study viewed school-related incidents (e.g., needing aid, failing a quiz) as indictments, far more monumental and meaningful than a momentary setback. Interviews revealed that the experimental video helped change minoritized students' mindsets. Factors that lead to an improvement of well-being were elevated confidence as students gained hope (Snyder, 2000) from the video that difficulties are normal, pass with time, and faced by all students, including other students of color who persisted to upperclassman status or recently graduated.

Participants also identified some factors that mediated the impact of the video intervention on sense of belonging. For instance, the intervention helped students reframe academic-related setbacks as normal, fleeting, and commonly experienced by many students, not just students of color. That helped improve interactions and relationships with others, especially SBP peers, staff, and advanced students upon whom participants could rely for advice. Feeling connected to others facing similar problems strengthened social bonds, encouraged honesty, fostered community, and nurtured individual's sense of belonging. While findings generally simplify results presented elsewhere about the importance of positive supportive relationships with staff and peers (Strayhorn, 2008a), the study breaks new ground by revealing how exposure to a brief belonging video intervention catalyzes mutual-sharing and common understandings that subsequently facilitate stronger social bonds for first-year college students of color at PWIs.

Another major contribution of this study is its demonstration that qualitative methods can be gainfully employed in higher education intervention research, much like it has been used in epidemiology and other health fields (Willms et al., 1990). What's revealed in this study through the comments and words of participants would be difficult to discern in a Likert-scale-based survey or federal database. Interviews offer at least plausible explanations of actual events or processes that shifted first-year students' mindsets, enhanced their confidence, and boosted their sense of belonging — what Miles and Huberman (1984) called local causality. Whether this brief video intervention would yield similar effects among younger or K-12 students, or other underrepresented students (e.g., foster youth, food insecure learners), is an important question for future research; as is uncovering the local causality of such effects, if any.

The results of this study are vitally important for several reasons. The first year of college is the period of time in which students develop the habits of mind upon which their subsequent success depends (Upcraft et al., 2005). Embedding effective interventions, like this brief experimental video, in SBPs for minoritized first-year students at PWIs holds promise for leveling expectations, raising awareness of campus supports, encouraging help-seeking, and boosting sense of belonging. This illustrates the "equity imperative" associated with belonging. By targeting necessary support to students early on, educators help level the playing field by reducing, if not removing, known barriers, gaps, and other racialized inequities (e.g., social stigma, stereotypes). 
The study has significant implications for practice. One group that might benefit from the results of this study includes SBP directors and staff. This study provides program directors with data about the initial worries, anxieties, and health behaviors of recently matriculated first-year students of color in a bridge program. It also demonstrates the positive influence that a brief belonging video intervention plays on their self-efficacy, well-being, and sense of belonging. SBP staff might use the results to anticipate the concerns of incoming students, incorporate prosocial coping skills in SBP curricula, and adopt similar interventions as a way of preventing minoritized students at PWIs from perceiving challenges as fixed deficits unique to themselves or indictments to their overall sense of belonging in college. While empirical support for video interventions in education is growing and likely to occupy a noticeable space in the author's future agenda, educators and SBP staff should note that catalyzing messages, lists, and vignettes can also be shared via email, social media, in-person panel discussions, guest speakers, campus clubs, advising, and one-on-one peer mentoring sessions, to name a few examples.

The study was significant in terms of future theory. To date, sense of belonging theory has focused on what belonging is, how it's defined, and best measured in research studies. Belonging theorists have also paid attention to delineating the core elements of the phenomenon and how it promotes learning and development in social domains like education (Strayhorn, 2019). The present study offers vivid insights into the effect of a brief belonging video intervention on firstyear college students of color, participating in a SBP. These data might be used to expand existing theory to include information about the local causal mechanism, specifically how academic messaging can alter students' subjective construal, recast adversities as common, temporal, and surmountable with support and time.

In conclusion, findings from the present study demonstrate that a brief belonging video intervention can enhance ethnic minority first-year students' sense of belonging at PWIs and positively alter the interpretive lens through which they construe or make meaning of schoolrelated adversities in college. The video can help first-year students of color reframe academic and personal challenges as normal, fleeting, non-personal, nonthreatening, and surmountable with time, support, help-seeking, and effort. The intervention under study also holds promise for improving racially minoritized first-year student's relationships with peers and others who may share some experiences in common by facilitating safe, trusting, racially-affirmative spaces and opportunities for them to communicate openly, practice vulnerability, and share resources which, in turn, nurtures community and a sense of belonging. Indeed, the absence of belonging is a structural problem, not an individual flaw, deficit, or deficiency - it simply exposes that there isn't an ecosystem in place to ensure this basic need is met for all students. The experimental video-its contents and characters - along with the SBP comprise the constellation of caring supports that can be institutionalized to enable college success.

\section{References}

Anderman, L. H., \& Freeman, T. M. (2004). Students' sense of belonging in school. In M. L. Maehr \& P. R. Pintrich (Eds.), Advances in motivation and achievement: Vol. 13 Motivating students, improving schools: The legacy of Carol Midgley (pp. 27-63). Elsevier.

Bailit, H. L., Formicola, A. J., Herbert, K. D., Stavisky, J. S., \& Zamora, G. (2005). The origins and design of the dental pipeline program. Journal of Dental Education, 69(2), 232-238.

Bui, K. (2002). First-generation college students at a four-year university: Background characteristics, reasons for pursuing higher education, and first-year experiences. College Student Journal, 36(1), 3-9. 
Carales, V. D., \& Nora, N. (2020). Finding place: Cognitive and psychosocial factors impacting Latina/o students' sense of belonging. Journal of Student Affairs Research \& Practice. https://doi.org/10.1080/19496591.2019.1662795

Civitci, N., \& Civitci, A. (2009). Self-esteem as mediator and moderator of the relationship between loneliness and life satisfaction in adolescents. Personality and Individual Differences, 47(8), 954-958.

Creswell, J. W., \& Plano Clark, V. L. (2007). Designing and conducting mixed methods research. SAGE Publications.

Denzin, N. K., \& Lincoln, Y. S. (2000). The discipline and practice of qualitative research. In N. K. Denzin \& Y. S. Lincoln (Eds.), Handbook of qualitative research (2nd ed., pp. 1-29). SAGE Publications.

Diehl, K., Jansen, C., Ishchanova, K., \& Hilger-Kolb, J. (2018). Loneliness at universities: Determinants of emotional and social loneliness among students. International Journal of Environmental Research and Public Health, 15(9), 1865-1879.

Driscoll, D. L., Appiah-Yeboah, A., Salib, P., \& Rupert, D. J. (2007). Merging qualitaive and quantitative data in mixed methods research: How to and why not. Ecological and Environmental Anthropology, 3(1), 19-28.

Felder, R. M., Felder, G. N., \& Associates. (1995). A longitudinal study of engineering student performance and retention. Journal of Engineering Education, 84, 151-174.

Fletcher, S. L., Newell, D. C., Newton, L. D., \& Anderson-Rowland, M. R. (2001). The WISE summer bridge program: Assessing student attitudes, retention, and program effects. Paper presented at the American Society for Engineering Education Annual Conference and Exposition, Albuquerque, NM.

Freeman, T. M., Anderman, L. H., \& Jensen, J. M. (2007). Sense of belonging in college freshmen at the classroom and campus levels. The Journal of Experimental Education, 75(3), 203220.

Gándara, P. (2001). Paving the way to postsecondary education: K-12 intervention programs for underrepresented youth.National Center for Education Statistics. http://files.eric.ed.gov/fulltext/ED458340.pdf

Gándara, P. (2002a). Meeting common goals: Linking K-12 and college interventions. In W. G. Tierney \& L. S. Hagedorn (Eds.), Increasing access to college: Extending possibilities for all students (pp. 81-103). State University of New York Press.

Gándara, P. (2002b). A study of high school Puente: What we learned about preparing Latino youth for postsecondary education. Educational Policy, 16(4), 474-495.

Garcia, P. (1991). Summer bridge: Improving retention rates for underprepared students. Journal of the Freshman Year Experience, 3(2), 91-105.

Garvey, J. C., Arámbula Ballysingh, T., Bowley Dow, L., Howard, B. L., Ingram, A. N., \& Carlson, M. (2020). Where I sleep: The relationship with residential environments and firstgeneration belongingness. College Student Affairs Journal, 38(1), 16-33.

Gopalan, M., \& Brady, S. T. (2020). College students' sense of belonging: A national perspective. Educational Researcher, 49(2), 134-137.

Guo, T.-C., \& Cheng, Z.-C. (2016). Sense of belonging based on novel posting. Online Information Review, 40(2), 204-217.

Harper, S. R. (2012). Race without racism: How higher education researchers minimize racist institutional norms. The Review of Higher Education, 36(1), 9-29.

Huo, Y., \& Kong, F. (2014). Moderating effects of gender and loneliness on the relationship between self-esteem and life satisfaction in Chinese university students. Social Indicators Research, 118, 305-314. 
Hurtado, S., \& Carter, D. F. (1997). Effects of college transition and perceptions of campus racial climate on Latino college students' sense of belonging. Sociology of Education, 70(4), 324345.

Jones, S. R. (2002). (Re)Writing the word: Methodological strategies and issues in qualitative research. Journal of College Student Development, 43(4), 461-473.

Kvale, S. (1996). InterViews: An introduction to qualitative research interviewing. SAGE Publications.

Lambert, N. M., Stillman, T. F., Hicks, J. A., Kamble, S., Baumeister, R. F., \& Fincham, F. D. (2013). To belong is to matter: sense of belonging enhances meaning in life. Personality $\begin{array}{llll}\text { and Social Psychology Bulletin, } & 39(11), & \text { 1418-1427. }\end{array}$ https://doi.org/10.1177/0146167213499186

Lincoln, Y. S., \& Guba, E. G. (1985). Naturalistic inquiry. SAGE Publications.

Maslow, A. H. (1954). Motivation and personality. Harper \& Row Publishers, Inc.

Miles, M., \& Huberman, A. (1984). Qualitative data analysis: A sourcebook for new methods. SAGE Publications.

Moeller, R. W., \& Seehus, M. (2019). Loneliness as a mediator for college students' social skills and experiences of depression and anxiety. Journal of Adolescence, 73, 1-13.

Moller-Wong, C., \& Eide, A. (1997). An engineering student retention study. Journal of Engineering Education, 86, 7-15.

Moustakas, C. (1994). Phenomenological research methods. SAGE Publications.

Myers, D., \& Schirm, A. (1999). The impacts of Upward Bound: Final report for Phase I of the national evaluation. Mathematica Policy Research.

Myers, R. D. (2003). College success programs. Pathways to College Network.

O'Cathain, A., \& et al. (2013). What can qualitative research do for randomised controlled trials? A systematic mapping review. BMJ Open, 3(6).

Ostrove, J. M., \& Long, S. M. (2007). Social class and belonging: Implications for college adjustment. The Review of Higher Education, 30(4), 363-389.

Panadero, E., Jonsson, A., \& Botella, J. (2017). Effects of self-assessment on self-regulated learning and self-efficacy: Four meta-analyses. Educational Research Review, 22, 74-98. https://doi.org/10.1016/j.edurev.2017.08.004

Patton, M. Q. (1990). Qualitative evaluation and research methods (2nd ed.). SAGE Publications.

Ronzi, S., Orton, L., Pope, D., Valtorta, N. K., \& Bruce, N. G. (2018). What is the impact on health and wellbeing of interventions that foster respect and social inclusion in communityresiding older adults? A systematic review of quantitative and qualitative studies. Systematic Reviews, 7(1), 26. https://doi.org/10.1186/s13643-018-0680-2

Sablan, J. R. (2014). The challenge of summer bridge programs. American Behavioral Scientist, 58(8), 1035-1050. https://doi.org/10.1177/0002764213515234

Sandelowski, M. (1996). Using qualitative methods in intervention studies. Research in Nursing \& Health, 19(4), 359-364.

Snyder, C. R. (2000). Hypothesis: There is hope. In C. R. Snyder (Ed.), Handbook of hope: Theory, measures and applications (pp. 3-21). Elsevier Science.

Soble, J. R., Spanierman, L. B., \& Liao, H. (2011). Effects of a brief video intervention on white university students' racial attitudes. Journal of Counseling Psychology, 58(1), 151-157.

Soni, V. (2019, July 14). There's a loneliness crisis on college campuses. LA Times. http://www.latimes.com/opinion/op-ed/la-oe-soni-campus-student-loneliness-20190714story.html 
Stebleton, M. J., Soria, K. M., \& Huesman, R. L. (2014). First-generation students' sense of belonging, mental health, and use of counseling services at public research universities. Journal of College Counseling, 17, 6-20.

Stolzenberg, E. B. (2018). The mental and physical well-being of incoming freshmen: Three decades of research. http://higheredtoday.org/2018/09/06/mental-physical-well-incomingfresshman-three-decades-research

Strayhorn, T. L. (2008a). The role of supportive relationships in facilitating African American males' success in college. NASPA Journal, 45(1), 26-48.

Strayhorn, T. L. (2008b). Sentido de pertenencia: A hierarchical analysis predicting sense of belonging among Latino college students. Journal of Hispanic Higher Education, 7(4), 301-320.

Strayhorn, T. L. (2011). Bridging the pipeline: Increasing underrepresented students' preparation for college through a summer bridge program. American Behavioral Scientist, 55(2), 142149. https://doi.org/10.1177/0002764210381871

Strayhorn, T. L. (2012). College students' sense of belonging: A key to educational success. Routledge.

Strayhorn, T. L. (2019). College students' sense of belonging : A key to educational success for all students (2nd ed.). Routledge.

Strayhorn, T. L. (2021). Analyzing the short-term impact of a brief web-based intervention on firstyear students' sense of belonging at an HBCU: A quasi-experimental study. Innovative Higher Education. https://doi.org/10.1007/s10755-021-09559-5

Strayhorn, T. L., \& Tillman-Kelly, D. L. (2015). Queering masculinity: Manhood and Black gay men in college. Spectrum: A Journal on Black Men, 1(2), 83-110.

Swail, W. S., \& Perna, L. W. (2002). Pre-college outreach programs: A national perspective. In W. G. Tierney \& L. S. Hagedorn (Eds.), Increasing access to college: Extending possibilities for all students (pp. 15-34). State University of New York Press.

Tashakkori, A., \& Teddlie, C. (1998). Mixed methodology: Combining qualitative and quantitative approaches. SAGE Publications.

Tashakkori, A., \& Teddlie, C. (2003). Handbook of mixed methods in social and behavioral research. SAGE Publications.

Tierney, W. G. (2002). Reflective evaluation: Improving practice in college preparation programs. In W. G. Tierney \& L. S. Hagedorn (Eds.), Increasing access to college: Extending possibilities for all students (pp. 217-230). State University of New York Press.

Upcraft, M. L., Gardner, J. N., \& Barefoot, B. O. (2005). Challenging and supporting the first-year student: A handbook for improving the first year of college. Jossey-Bass.

Villalpando, O., \& Solórzano, D. G. (2005). The role of culture in college preparation programs: A review of the research literature. In W. G. Tierney, Z. B. Corwin, \& J. E. Colyar (Eds.), Preparing for college: Nine elements of effective outreach (pp. 13-28). State University of New York Press.

Walton, G. M., \& Cohen, G. L. (2011). A brief social-belonging intervention improves academic and health outcomes of minority students. Science, 331(March), 1447-1451.

Whitt, E. J. (1991). Artful science: A primer on qualitative research methods. Journal of College Student Development, 32, 406-415.

Willms, D. G., Best, J. A., Taylor, D. W., Gilbert, J. R., Willson, D. M. C., Lindsay, E. A., \& Singer, J. (1990). A systematic approach for using qualitative methods in primary prevention research. Medical Anthropology Quarterly, 4(4), 391-409.

Yeager, D. S., \& Walton, G. M. (2011). Social-psychological interventions in education: They're not magic. Review of Educational Research, 81, 267-301. 


\section{Notes on Contributor}

Terrell Lamont Strayhorn, PhD, is Provost and Senior Vice President of Academic Affairs at Virginia Union University, where he also serves as tenured Professor of Urban Education in the Evelyn Reid Syphax School of Education and Director of the Center for the Study of Historically Black Colleges and Universities (HBCUs). He has published 11 books and over 150 refereed journal articles, chapters and reports, directing much attention to positing sense of belonging as a basic need, human right, and significant determinant of racial (in)equities and disparities in education and corporate settings. He received his $\mathrm{PhD}$ from Virginia Tech.

Manuscript received October 18, 2021

Final revision received November 27, 2021

Accepted December 4, 2021 